\section{Treatment Gap in Childhood Epilepsy (TGCE): Pakistan Regional Study in Under- Resourced Community}

Keywords: Qualitative research; Childhood epilepsy; Epilepsy treatment gap; Adherence; Antiepileptic drugs; Interventions; Bhakhar, Pakistan

\begin{abstract}
Background: The epidemiological data on childhood epilepsy, essential to plan services in resource constrained developing nations, is scarce. Identifying the determina nts of trea tment gaps in child hood epilepsy is essential to provide optimal care for childhood epilepsy.
\end{abstract}

Study type and duration: This was a descriptive cross-sectional community based study conducted from April 14, 2014 to April 16, 2014, conducted at two privately owned hospitals in Bhakhar, Punjab, Pakistan.

Objective: To evaluate the treatment gap and its determinants in childhood epilepsy in Bhakhar city.

Methods: We conducted a random three-stage sampling of children being treated as epileptic or had epileptic seizures. Subjects were identified through two days of free paediatric neurology camps, one day at each hospital. A twenty-item screening questionnaire was used to identify the presence of epilepsy. Definitions provided by Intemational League against Epilepsy (ILAE) were used to classify the screened positive subjects as epilepsy. The treatment gap and factors associated with it were assessed and calculated by two pediatric neurologists in consensus. Information obtained from subjects and their care givers included: demographic characteristics, current and past trea tment options utilized, rea sons for trea tment options used and reasons for nonadherence to antiepilepsy drugs (AEDs).

Results: 130 children with epilepsy were enrolled and epilepsy treatment gap of $90 \%$ was documented among these patients. Nonadherence was observed in $70(54 \%)$ patients, $50(38 \%)$ patients were adherent to the prescribed AEDs, whereas $10(8 \%)$ patients had never used any antiepileptic drug; on the other hand $61 \%$ of the total patients were being treated with polytherapy ( $\geq 2 A E D s)$. The most common causes of TGCE were cost, untrained health professionals, poor/no counseling to the parents, nonavailability of AEDs and younger age of the patients. No national or intemational organization was found attempting to decrease TGCE in Bhakhar city.

Conclusion: Owing to the marked scarcity of comprehensive childhood epilepsy care centers in under-resourced communities of Pakistan, only a minority of patients are being treated optimally. Determining the appropriate interventions need to narrow the treatment gap and these rely critically upon understanding the magnitude of treatment gap and the driving forces behind it.

\section{Abbreviations}

CWE: Children with Epilepsy; CETG: Childhood Epilepsy Treatment Gap; LMICs: Low and Middle Income Countries; RPCs: Resource Poor Countries; AEDs: Antiepileptic Drugs; CHWs: Community Health Workers

\section{Journal of Neurology and Psychology}

Muhammad Akbar Malik*, Hamza Malik, Muhammad Waseem Wali, Nadeem Shabbir and Muhammad Saeed

The Brain Associates Institute, 218 D Model Town, Lahore, Pakistan

\section{*Address for Correspondence}

Muhammad Akbar Malik, Consultant Paediatric Neurologist, The Brain Associates Institute, 218 D Model Town, Lahore, Pakistan, E-mail: docmalikpk2000@yahoo.co.in

Copyright: (c) 2015 Malik MA, et al. This is an open access article distributed under the Creative Commons Attribution License, which permits unrestricted use, distribution, and reproduction in any medium, provided the original work is properly cited.

Submission: 24 November 2014

Accepted: 29 December 2014

Published: 03 January 2015

Reviewed \& Approved by: Dr. Maromi Nei, Associate Professor, Department of Neurology, Thomas Jefferson University Hospital, USA

\section{Introduction}

Epilepsy is among one of the most common non communicable diseases in the world and accounts for $0.5 \%$ of the whole disease burden. Among 50 million people with epilepsy worldwide, $80 \%$ of them are found in developing countries. Almost $80-90 \%$ of these patients are not receiving adequate treatment [1]. This huge treatment gap may be due to the limited knowledge, poverty, cultural beliefs, stigma, poor health delivery infrastructure like inadequate supplies of antiepileptic drugs and shortage of trained health care workers $[2,3]$. This is even more worrisome considering the fact that incidence of epilepsy is higher in the first two decades of life in the first two decades of life [4]. Majority of persons with epilepsy live in low and middle income countries (LMICs) and have limited access to effective treatment [5].

The resultant epilepsy treatment gap (ETG) has been defined as 'the difference between the number of people with active epilepsy and the number whose seizures are being appropriately treated in a given population at a given point of time, expressed as percentage [6]. This definition includes diagnosis, poor data collection and documentation of health statistics. The weaknesses in the health systems of most susceptible LMICs coupled with the stigma associated with epilepsy make the estimation of CETG highly variable. It has been proposed as an important parameter for access to care and quality of care across health systems and paediatric population. There is an average gap of approximately $85 \%$ for low- income countries [5-7]. Where available, epilepsy care in low-income countries remains extremely basic and antiepileptic drugs (AEDs) are delivered by nonphysician healthcare workers who have no recourse to electroencephalography (EEG), neuroimaging, serum-drug level monitoring or specialist referral [8]. Most studies concerning ETG from the LMICs have focused on entire populations $[5,7]$. For these and other programs to be effective in bridging the ETG it is important to continually appraise treatment of epilepsy among vulnerable populations, such as children with epilepsy (CWE), in susceptible communities. The magnitude of epilepsy treatment gap in children and its causes is not well studied in developing countries. The limited amount of literature suggests 
that health system issues as well as individual perceptions are both responsible for the treatment gap [9]. Pakistan is one of the developing countries in the world and it is not uncommon to see huge untreated epilepsy patients in our country [10]. Although substantial economic development and improvement of health services have occurred, still Pakistan is a heterogeneous and resource-constrained country. People suffering from epilepsy in country like ours do not have good quality life because of their poor epilepsy control. Data collection is the first step toward better classification and understanding of the problems, which the individuals with epilepsy and their families face. These data are critical to position us to make informed decisions on deploying limited resources to improve the life of individuals and their families. For this purpose, this study was done amongst patients attending free camps for childhood neurological diseases in two privately owned hospitals in Bhakhar city. A preparatory step for this endeavour is to examine the existing health care-delivery system in the city. The objectives of the research were three-fold: firstly to create awareness about childhood epilepsy in the public; secondly gather data on the prevalence of childhood epilepsy treatment gap (CETG); and thirdly to ascertain the contributing factors for CETG in childhood epilepsy in the specific population.

\section{Subjects and Methods}

The study was conducted by cross-sectional snap survey of free camps for childhood epilepsy and other paediatric neurological disorders under the supervision of paediatric neurologists in Bhakhar city. The camps were organized by the two privately owned hospitals and these hospitals were chosen randomly. One whole day was spent at each hospital. This city has district headquarter hospital and paediatric department headed by a qualified paediatrician but no paediatric neurologist is available in the city. There are many private hospitals and clinics providing all sorts of paediatric services. A medical college has already been approved and announced for the city. Also, there are traditional healers, who are thought to possess medicinal antidotes to the occurrence of epilepsy and other neurological diseases in the children.

\section{Definition of study population and terms}

The study population comprised of children and adolescents age $\leq 18$ years, whose ages were ascertained by evidence of birth records, school record or oral evidence by the carers/patients. For epidemiological surveys, and in this study, epilepsy was defined as: recurrent unprovoked seizures occurring at least 24 hours apart while active epilepsy was defined as occurrence of unprovoked epileptic seizures on different days in the preceding five years [11,12]. The epilepsy treatment gap had two components: those not accessing or unable to access biomedical facilities for diagnosis and treatment (primary TG) and, if accessing biomedical treatment, those not adhering to the prescribed AED (Secondary TG). A determinant of the childhood epilepsy treatment gap (CETG) was defined as any factor that caused, contributed to or influenced adequate treatment of epilepsy among the study population.

\section{Conduct of study}

Before conducting the study a through advertisement about these free camps for children with neurological disorders was done for 2 weeks through local news papers, pamphlets, posters, banners at every possible place and visiting all private hospitals. Special help was sought from Mosque Imams and school teachers for announcing the camps and encouraging the community to visit these camps. The study was conducted in two phases: phase I was for training and developing research tools. In the first phase the authors and research assistants (local as well as visiting) met with the authorities of these two privately owned hospitals $(1+2)$. A 1-day training workshop was conducted at Niazi Hospital in Bhakhar City, under the supervision of the Paediatric Neurologist (Malik- $1^{\text {st }}$ author).

A 20 items questionnaire was adapted and modified from an extensively validated questionnaire used in Ecuador, translated into local Urdu and Punjabi languages in the form of specially designed proforma [9]. At the meeting the aim of the study was presented and communal consent sought. All members of the group could speak one of the traditional languages fluently. At the end of the workshop, competency of the research team, efficacy of the questionnaire and proforma was assessed. A pilot study was conducted on 5 patients for testing feasibility and applicability of the tools then the necessary modifications were done. Those patients were assessed again on the modified questionnaire sheet. The aim of the study and the component of the tools were explained to patients by the researchers at the beginning of data collection. They were assured that the information collected would be treated confidentially and that it would be used only for the purpose of study.

The patients were assigned randomly to the two research teams until all the patients were assessed and interviewed each day at each hospital. Each research team administered a structured questionnaire to the patients (subjects) and/or their parents or caregivers independently and as applicable. Parameters assessed using the structured questionnaire included: Age, sex, clinical features of epilepsy, treatment options utilized, and diagnostic investigations, reasons for using the treatment options and follow up. All questionnaires were administered anonymously, both for the patients as well as for the treating bodies. All interviews were recorded in local language and subsequently translated into English. All those children who were diagnosed with active epilepsy were assessed by the paediatric neurologists and consensus was made about the diagnosis and appropriateness of the epilepsy treatment being commenced. All those identified as having active epilepsy and their caretakers were introduced to the paediatric neurologists in groups, for counseling, investigations (possible and if required), awareness creation about childhood epilepsy, were prescribed and guided according. Consent was regarded automatically given by the carers/patients when they agreed to answer the questionnaire. Patients who presented with seizures not classified as epilepsy, as per the existing guidelines (ILAE), those who did not give consent and those above the age18 years were excluded.

\section{Antiepileptic Drug (AED) treatment data}

The drug treatment data included the number of AEDs (monotherapy/polytherapy), generic/brand name, doses and duration of treatment for each patient. These details were obtained verbally and/or from the prescription orders/patient's record. Details of dose administered (prescribed daily dose - PDD) was collected along with the number of times each AED prescribed to the patient. 
Citation: Malik MA, Malik H, Wali MW, Shabbir N, Saeed M. Treatment Gap in Childhood Epilepsy (TGCE): Pakistan Regional Study in Under-Resourced Community. J Neurol Psychol. 2015;3(1): 7.

The data from every patient being diagnosed and treated as epilepsy was collected, entered in a specially designed form and transferred into a Microsoft Office Excel worksheet, by the investigators.

Ethical approval for the study was obtained from the Research and ethics committee of the Brain Associates Institute Lahore.

\section{Results}

The total number children who visited these camps were 210 out of these 180 constituted the child and adolescent population with recurrent seizures. Of these 180 children and adolescents with recurrent seizures who were interviewed, 130 (subjects) reported to have epileptic seizures and seeking treatment for epilepsy from different sources including government a health facilities. This analysis is of treatment gap, whereas investigational gap over diagnosis would be analyzed in this other report. The age range of the subjects was 4 months to 18 years (mean $10 \pm 3.7$ years). There was a male preponderance $(n=70,54 \%)$ with a Male: Female ratio of 1.2:1. Most $(n=73,56 \%)$ of the subjects were $5-15$ years of age (Table 1 ).

Of the 130 children with epilepsy who were interviewed, 10(8\%) never sought a physician, 120 (92\%) reported seeking/ sought treatment for epilepsy from an allopathic doctor or health facility at some stage of their disease as their primary source of AEDs, of whom $70(58 \%)$ stopped or were using treatment improperly for different reasons (Table 2).

There were different reasons for non-adherence to AEDs and were usually multiple in each subject. Twenty two (31\%) patients in nonadherent group of this study thought that the main cause of epilepsy is supernatural, linked with evil spirit and demonic attack and discontinue the prescribed $\operatorname{AED}(\mathrm{s})$. The most common causes of non-adherence to AEDs were cost and poor/no counselling to parents by the treating physician (Table 3 ).

Other factors associated with failure to seek treatment were convincing by faith healers/homeopathic physicians. Non-availability of AEDs to health facilities and unaffordable prices of for AEDs for the parents were the causes in a significant no of patients (Table 3). We found that attributed causes of the large TG in our study were multiple and overlapped between these associated factors. The formal education of parents/caretakers was assessed by self- reporting in the survey and on-site observations by the trained interviewers. Absence of formal education of parents/caretakers had direct relationship with the magnitude of treatment gap (Table 4).

The attributed causes with the highest medians were related to the health systems mainly: cost of treatment, inadequate skilled man power and unavailability of drugs.

As $92 \%$ of these subjects consulted medical doctors but still treatment gap on the average was $90 \%$. The patients and families had to pay beyond their means for the most commonly prohibitively expensive second-generation drugs (Valproate, Levetiracetam, Oxcarbamazipine and Lamotrigine). That was more than $30 \%$ of the monthly income in most of the cases. Erratic disorganized pattern of getting treatment from different levels of expertise was not effective in decreasing TGCE. The findings of this survey show that superstitions and cultural beliefs influence very little to seek treatment from traditional healers as compared to that of allopathic practitioners (Table 5).

There was wide variability in therapeutic practices between the different treating bodies. Drug choice was often largely dependent on the level of treating physicians without consideration of socioeconomic status of the patient. There was excessive (80\%) reliance on costly second generation $\operatorname{AED}(\mathrm{s})$ and unnecessary polytherapy, often without rationale. The primary care physicians, neurosurgeons, adult psychiatrists were not usually equipped with the knowledge about the classification of seizures, epilepsies, epilepsy syndromes, and specific efficacy of various AEDs. The doses of AEDs prescribed by the treating physicians were inappropriate and/or suboptimal. In this survey 8 percents of the children with epilepsy (CWE) never received any antiepileptic drug; on the other hand $61 \%$ of these were being treated with polytherapy (Table 6).

\section{Discussion}

The epilepsy treatment gap is over $75 \%$ in low-income countries and over $50 \%$ in lower middle- and upper middle-income countries, while many high-income countries had gaps of less than $10 \%$. However, treatment gap varies widely both between and within

Table 1: Distribution of epileptic patients by age group \& sex in Bhakhar- Pakistan

\begin{tabular}{|c|c|c|c|c|c|}
\hline Age group & Male & Female & Total & Percentage & Treatment Gap (\%) \\
\hline 2 Mon - 2 yrs & 20 & 10 & 30 & 23 & $29 / 30=98 \%$ \\
\hline$>2$ yrs $-5 y r s$ & 8 & 12 & 20 & 15 & $19 / 20=94 \%$ \\
\hline$>5 \mathrm{yrs}-10 \mathrm{yrs}$ & 25 & 20 & 45 & 35 & $41 / 45=92 \%$ \\
\hline$>10$ trs -15 yrs & 12 & 16 & 28 & 22. & $25 / 28=88 \%$ \\
\hline$>15$ yrs - 18 yrs & 05 & 02 & 07 & 5 & $6 / 8=80$ \\
\hline Total: $130(100 \%)$ & $70(54 \%)$ & $60(46 \%)$ & 130 & $(100 \%)$ & Average $=90 \%$ \\
\hline
\end{tabular}

Table 2: Treatment pattern of Childhood Epilepsy $(n=130)$.

\begin{tabular}{|c|c|c|c|}
\hline No. & Treatment & No. & Percentage \\
\hline 1 & Never consulted an allopathic physician & 10 & 8 \\
\hline 2 & Started AED(s) but stopped/improper use of AED(s) & 70 & 54 \\
\hline 3 & Adherent to $\mathrm{AED}(\mathrm{s})$ treatment & 50 & 38 \\
\hline 4 & Total & 130 & 100 \\
\hline
\end{tabular}


Citation: Malik MA, Malik H, Wali MW, Shabbir N, Saeed M. Treatment Gap in Childhood Epilepsy (TGCE): Pakistan Regional Study in Under-Resourced Community. J Neurol Psychol. 2015;3(1): 7.

ISSN: 2332-3469

Table 3: Reasons for non- adherence to AEDS(s), ( $n=70)$.

\begin{tabular}{|l|l|c|}
\hline No. & Reasons for non-adherence to AED(s) & No. \\
\hline 1 & Cost & 65 \\
\hline 2 & Poor/no counseling by the treating physician(s) & 93 \\
\hline 3 & No response to AED(s) & 57 \\
\hline 4 & Counseling by faith healers/homeopathic doctors & 30 \\
\hline 5 & Non availability of AED(s) & 22 \\
\hline
\end{tabular}

Table 4: Distribution of seizure treatment gap in association with formal education of parents/caretakers.

\begin{tabular}{|l|c|c|}
\hline Parents/ Caretakers Education & No. & TG \\
\hline No education or not clear & 30 & 29 \\
\hline Primary education & 50 & 48 \\
\hline Secondary education & 30 & 25 \\
\hline Higher education & 20 & 16 \\
\hline
\end{tabular}

Average treatment Gap=90\%

Table 5: Association of treating bodies with treatment gap of childhood epilepsy.

\begin{tabular}{|c|c|c|c|c|c|}
\hline No. & Treating Body & No. & Prescription pattern & TG & Reasons(s) \\
\hline 1 & Faith Healers & 10 & Homeopathic drugs & $10 / 10=100 \%$ & No knowledge of CE \\
\hline 2 & Primary Physicians & 30 & 1st Gen AEDs & $29 / 30=98 \%$ & Improper drugs and dosages +cost \\
\hline 3 & Paediatricians & 30 & 1st Gen AEDs & $27 / 30=90 \%$ & Improper drugs and dosages + cost \\
\hline 4 & Adult Neurologists & 20 & 1st Gen AEDs & $15 / 20=75 \%$ & Improper drugs and dosages + cost \\
\hline 5 & Adult Psychiatrists & 15 & 1st Gen AEDs & $14 / 15=93 \%$ & Improper drugs and dosages + cost \\
\hline 6 & Paediatric Neurologists & 15 & 2nd Gen AEDs & $13 / 15=87 \%$ & Cost and counseling \\
\hline 7 & Neurosurgeons & 10 & 2nd Gen AEDs & $9 / 10=90 \%$ & Improper drugs and dosages+ cost \\
\hline
\end{tabular}

Average TG=90\%; TG: Treatment Gap; CE: Childhood Epilepsy

Table 6: AEDs Prescription patterns.

\begin{tabular}{|c|c|c|c|}
\hline No. & AED Prescription & No. & Percentage \\
\hline 1 & Homeopathic drugs or no drug & 10 & 8 \\
\hline 2 & 1 AED & 40 & 31 \\
\hline 3 & 2 AEDs & 30 & 23 \\
\hline \multirow[t]{2}{*}{4} & $\geq 3$ AEDs & 50 & 38 \\
\hline & Total & 130 & 100 \\
\hline
\end{tabular}

countries [7]. In agreement we documented very high treatment gap (90\%) in children and adolescents with epilepsy and it was almost $100 \%$ in children $\leq 2$ years of age and was lower in adolescents of $\geq 15$ years of age. In our patient's age ranged from 4 months to 18 years (mean $10 \pm 3.7$ years) with Male: Female ratio of 1.2:1. In agreement with our study, age specific rates are higher in $1^{\text {st }}$ decade of life, especially below the age of 2 years [13]. In contrast to this, Eseigbe etc, reported age range of 4-19 years (mean $14 \pm 4.7$ years) in CWE with Male:Female ratio of $4.8: 1$, and have documented treatment gap of $100 \%$ among these children [14]. We could not explain the reasons for these variations in age and sex among CWE. Pakistan is a developing country with mixed heterogeneous socioeconomic structure. Bhakhar is the last district of South- Punjab and main community is semi-urban and under-resourced. Varying ETG has been confirmed in different communities as: in a highly literate population of Kerala, a treatment gap of $38 \%$ and a treatment gap of
$50 \%$ in Calicut district of Kerala has been found [15,16]. The large disparities of CETG are found within poor countries, particularly between the poorer areas (rural or semi-urban settlements) and more affluent urban areas [5].

In the resource-poor countries, a large proportion of patients with epilepsy, despite being diagnosed and initiated on AED treatment, soon discontinue the treatment. In epidemiological surveys, such patients would be categorized as not being on treatment. Das et al. coined the term 'secondary treatment gap' to designate this phenomenon [17]. In the majority of the cases in our report the CETG was secondary, as $92 \%$ were started on AEDs but later $54 \%$ stopped their children's treatment (Table 1). It is also comparable to what in the developing countries, as different studies have showed that 30 $50 \%$ of the patients with epilepsy were reported to be nonadherent to the extent of interfering with optimal treatment and seizure control [18]. 
Various reasons have been given for the discontinuation of treatment (nonadherence) leading to the high TGE. Ninety percent of the patients discontinue due to the cost factor [19]. Adherence to a drug regimen is defined as the extent to which patients take drugs as prescribed by their health-care providers [20]. The commonest reason given for missing drugs was lack of drugs due to their high cost of AEDs and consultants consultation fees, as reported by $70(54 \%)$ of our study participants. This is similar to what has been reported by Faris et al. and Snodgrass et al., respectively [21,22]. The cost of drugs limits caregivers from purchasing them in case they are not available free or at a very low cost. Similarly Nazziwa et al. reported that the commonest reason given for missing drugs was lack of drugs due to their high cost as reported by $36(48.7 \%)$ of study participants comprising of children and adolescents [23]. None of the carers/ patients reported intentional nonadherence: this may be due selfreporting bias.

It appears that successful interactions with medical personnel can increase adherence. Gopinath et al. investigated the patient perspective of the doctor-patient relationship and found that both the number of visits and effective communication between the two promoted adherence [24]. Similar to this, we found that in $57 \%$ of the patient with secondary gap, poor or no counseling by the treating physician was a contributing factor. For patients who are unclear about the importance of following AED routines, various programs may be of benefit particularly in cases involving children and adolescents [25]. Educational and counseling programs may be a method of improving adherence; discussion with patients about seizures and treatment do appear to show higher levels of adherence [26].

Low treatment adherence is strongly associated with uncontrolled seizures among epilepsy patients [27]. A study that compared two epilepsy patient groups (non-adherent patients, $\mathrm{n}=298$; adherent patients, $\mathrm{n}=110$ ) also found non-adherence to be associated with reduced seizure control [28]. Although it is widely accepted that nonadherence leads to poor seizure control, our findings also suggest that uncontrolled seizures may, paradoxically, contribute to nonadherence. As 30(43\%) of nonadherent patient in our study group discontinue the drugs because there was inadequate seizure control.

Unfortunately, in most developing countries both the choice and supply of drugs are limited. Furthermore, in inadequate and poorlyresourced health care systems, any type of antiepileptic drug is usually in short supply. In such systems the normal determinants for drug treatment are the drug's cost and availability [29]. In agreement, we documented that in 20 patients, nonadherence was due the nonavailability of the prescribed drugs. In view of such problems concerning the supply of antiepileptic drugs, it has been argued that the non-availability of antiepileptic drugs is the most important obstacle to the care of people with epilepsy [30-32]. It would seem then that not the diagnosis of epilepsy but the nonavailability of AEDs in developing countries is both a cause of the treatment gap and probably the single most important obstacle in bridging this gap.

The average duration of time before starting appropriate AEDs is less than one month for children who received no complementary therapy, and 22 months for children receiving treatment from traditional healers, indicating the importance of education of family [33]. At the time of epilepsy onset and diagnosis, most patients and families probably know as much about epilepsy as the general public does, and their knowledge does not always improve in the period following diagnosis [34]. Similarly, we documented higher CETG in children whose parents had lesser formal education (Table 4). We observed that modern knowledge was very uncommon in parents with lower formal education and, when present, was related to the treatment of crises, rather than to the long term treatment (prevention of subsequent crises). In contrast to this, in the highly literate population of Kerala, southern India, a treatment gap rate of $38 \%$ was documented [16].

Holy persons like wali, fagir or sheikh, all are Muslims' clerics, have the privilege of exercising power through the Baraka (blessing) or intercession (shifaa) acquired from their ancestors and the blessed knowledge they have learned. These holy persons use their blessing of God to heal through prayer, charms, summons and amulets [35]. This resulted in nonadherence in about one-third of our study population. This is similar to the world wide believes that supernatural and spirits influence human being and affect their wellbeing and health especially in epilepsy [36-38].

If the treatment of epilepsy is not systematic and comprehensive it cannot be regarded as adequate [39]. "Sadly, adequate facilities for diagnosis, treatment and on-going management of childhood epilepsy were virtually non-existent in Bhakhar city". We documented that there was clear scarcity of epilepsy-trained health workers in Bhakhar city. The referral of patients between the primary, secondary, and tertiary health care systems was inadequate. Of the 130 patients with existing epilepsy 50 patients $(38 \%=11.5 \%$ by paediatric neurologist, $11.5 \%$ by adult psychiatrists and $15 \%$ by adult neurologist) had been seen by the epilepsy specialists at some time but still the CETG was very high (Table 3). These subspecialists were practicing in cosmopolitan cities and most probably were not very well aware about the socioeconomic status of these patients. Brown et al. stated that $20-40 \%$ of patients with epilepsy would require input from a specialist epilepsy service although their recommendations were not specifically for children [40]. The referral rate to specialist paediatric neurologists is, however, inevitably influenced and limited by resources. Parents and clinicians may not always agree on epilepsy management decisions as they may have differing perceptions and beliefs [41]. This may cause very high treatment gap, as observed in our study population. One of the most important roles for epilepsy specialists at the tertiary referral centers in resource-poor countries should be the continuing medical education of other medical practitioners down the line but we did not observe any such activity in Bhakhar city.

Regionally representative population-based data for the childhood epilepsy treatment gap and more data characterizing epilepsy-specific resources available for care in resource-poor regions would improve future cross-country comparisons [9]. Given that nonadherence is frequent, may compromise the benefits of $\operatorname{AED}(\mathrm{s})$ therapy, may complicate interpretation of clinical response, and can be addressed through evidence-based interventions, treating physicians should consider routinely assessing adherence to $\operatorname{AED}(\mathrm{s})$ therapy in all patients with childhood epilepsy. Empowering primary health-care workers to diagnose and start treatment might significantly reduce the treatment gap and the disparities between urban affluent and underresourced communities. Large community based trials in China and Brazil conducted by the ILAE/IBE/WHO Global Campaign Against 
Citation: Malik MA, Malik H, Wali MW, Shabbir N, Saeed M. Treatment Gap in Childhood Epilepsy (TGCE): Pakistan Regional Study in Under-Resourced Community. J Neurol Psychol. 2015;3(1): 7.

Epilepsy have demonstrated that epilepsy can be effectively treated at a community level with inexpensive drugs by healthcare workers with basic training $[42,43]$. In addition to community based epilepsy care, our study suggests that the epilepsy treatment gap can only be reduced if poverty and inequalities of healthcare, neurological and epilepsy resources are dealt with at the local and national levels.

\section{Strengths and Weaknesses of the Study}

The study strength is the evaluation of CETG involving community physicians (key informants) for study participants in addition to the self-report, right in the community. The study adopted the strategy of "Top-Down" (traveling of experts to the out-reach area) and "Bottom-Up" (local health care providers-key informants) for catching maximum patients and for reliable information. The use of focus groups discussions in addition to the individual interviews also led to a better understanding of reasons for nonadherence and enabled getting participants' ideas on how this could be improved. To our knowledge, this study is the first to examine CETG in Pakistan; however, several limitations are noted with implications for future research. 1) CETG was measured using patient report, and patients may have overestimated their adherence to AEDs [44]. 2) There is also no gold standard to define or assess non-adherence in surveybased studies and definitions used in the literature have varied [45]. 3) The number is small since it was an exploratory study, as larger numbers are needed to be more confident about the outcome data. 4) The study was limited to one geographic locality, one of the 36 districts of whole Punjab and there is diversity of socioeconomic status of the population in each district. 5) Finally, this study did not evaluate the AEDs nonadherence in the rural population the District Bhakhar. These limitations should be considered in future studies on nonadherence to AEDs among patients with childhood epilepsy in under-resource communities.

\section{Conclusion}

Epilepsy treatment gap among children with epilepsy attending the paediatric neurology outpatient camps in an under-resourced community as assessed by self-report was high, at $90 \%$. The causes of the epilepsy treatment gap that were identified in this study in rank order are: cost of treatment, inadequate skilled manpower, pour counseling of the treating physicians, cultural beliefs about the causation, unavailability of drugs, use of traditional medicine, less education of carers and younger age of the patients. The specific interventions should be able to identify those who have epilepsy, provide cheap, effective and affordable drugs, subsidize cost of investigations, ensure intercurrent supervision of management, and facilitate training and provision of childhood epilepsy care specialists.

\section{References}

1. World Health Organization (2012) Epilepsy. Fact sheet N999.

2. World Health Organization (2001) International classification of functioning disability and health (ICF). Geneva: WHO.

3. Leonardi M, Ustun TB (2002) The global burden of epilepsy. Epilepsia 43 21-25.

4. Mikati MA (2011) Seizures in childhood. In: Kliegman RM, Stanton BF, St. Geme JW, Schor NF, Behrman RE, editors. Nelson Textbook of Pediatrics, 19th ed. Philadelphia: WB Saunders Company, p. 2013-2017.

5. Ngugi AK, Bottomley C, Kleinschmidt I, Sander JW, Newton CR (2010)
Estimation of the burden of active and life-time epilepsy: a meta-analytic approach. Epilepsia 51: 883-90.

6. Chin JH (2012) Epilepsy treatment in sub -Saharan African: closing the gap. Afr Health Sci 12: 186-192.

7. Meyer AC, Dua T, Ma J, Saxena S, Birbeck G (2010) Global disparities in epilepsy treatment gap: a systematic review. Bull World Health Organ 88: 260-266.

8. Birbeck GL, Molyneux ME, Kaplan PW, Seydel KB, Chimalizeni YF, et al. (2010) Blantyre Malaria Project Epilepsy Study (BMPES) of neurological outcomes in retinopathy-positive paediatric cerebral malaria survivors: a prospective cohort study. Lancet Neurol 9: 1173-1181.

9. Mbuba CK, Ngugi AK, Newton CR, Carter JA (2008) The epilepsy treatment gap in developing countries: a systematic review of the magnitude, causes and intervention strategies. Epilepsia 49: 1491-1503.

10. Malik MA, Akram RM, Tarar MA, Sultan A (2011) Childhood Epilepsy. J Coll Physicians Surg Pak 21: 338-243.

11. (1993) Guidelines for epidemiological studies on epilepsy. Commission on Epidemiology and Prognosis of the International League Against Epilepsy. Epilepsia 34: 592-596.

12. Dent W, Helbok R, Matuja WB, Scheunemann S, Schmutzhard E (2005) Prevalence of active epilepsy in a rural area in South Tanzania: a door-todoor survey. Epilepsia 46: 1963-1969.

13. Udani V (2005) Pediatric epilepsy -- an Indian perspective. Indian J Pediatr 72: 309-313.

14. Eseigbe EE, Nuhu FT, Sheikh T, Adama SJ, Eseigbe P, (2014) Factors associated with treatment gap in children and adolescents with epilepsy in a rural Nigerian community. Niger J Paediatr 41: 22-27.

15. Radhakrishnan K, Pandian JD, Santhoshkumar T, Thomas SV, Deetha TD, et al. (2000) Prevalence, knowledge, attitude, and practice of epilepsy in Kerala, South India. Epilepsia 41: 1027-1035.

16. Hackett RJ, Hackett L, Bhakta P (1997) The prevalence and associated factors of epilepsy in children in Calicut District, Kerala, India. Acta Paediatr 86: $1257-1260$

17. Das K, Banerjee M, Mondal GP, Devi LG, Singh OP, et al. (2007) Evaluation of socio-economic factors causing discontinuation of epilepsy treatment resulting in seizure recurrence: a study in an urban epilepsy clinic in India. Seizure 16: 601-607.

18. Leppik IE (1988) Compliance during treatment of epilepsy. Epilepsia 29: S79-S84.

19. Mani KS, Rangan G, Srinivas HV, Kalyanasundaram S, Narendran S, et al. (1998) The Yelandur study: a community based approach to epilepsy in rural south India--epidemiological aspects. Seizure 7: 281-288.

20. Osterberg L, Blaschke T (2005) Adherence to medication. N Engl J Med 353: 487-497.

21. Al-Faris EA, Abdulghan MH, Mahdi AH, Salih MA, Al-Kordi AG (2002) Compliance with appointments and medications in a pediatric neurology clinic at a University Hospital in Riyadh, Saudi Arabia. Saudi Med J 23: 969-974.

22. Snodgrass SR, Vedanarayanan VV, Parker CC, Parks BR (2001) Pediatric patients with undetectable anticonvulsant blood levels: comparison with compliant patients. J Child Neurol 16: 164-168.

23. Nazziwa R, Mwesige AK, Obua C, Ssenkusu JM, Mworozi E (2014) Adherence to antiepileptic drugs among children attending a tertiary health unit in a low resource setting. Pan Afr Med J 17: 44.

24. Gopinath B, Radhakrishnan K, Sarma PS, Jayachandran D, Alexander A (2000) A questionnaire survey about doctor-patient communication, compliance and locus of control among South Indian people with epilepsy. Epilepsy Res 39: 73-82.

25. Asadi-Pooya AA (2005) Drug compliance of children and adolescents with epilepsy. Seizure 14: 393-395 
Citation: Malik MA, Malik H, Wali MW, Shabbir N, Saeed M. Treatment Gap in Childhood Epilepsy (TGCE): Pakistan Regional Study in Under-Resourced Community. J Neurol Psychol. 2015;3(1): 7.

26. Shope JT (1988) Compliance in children and adults: review of studies. Epilepsy Res Suppl 1: 23-47.

27. Jones RM, Butler JA, Thomas VA, Peveler RC, Prevett M (2006) Adherence to treatment in patients with epilepsy: associations with seizure control and illness beliefs. Seizure 15: 504-508.

28. Hovinga CA, Asato MR, Manjunath R, Wheless JW, Phelps SJ, et al. (2008) Association of non-adherence to antiepileptic drugs and seizures, quality of life, and productivity: survey of patients with epilepsy and physicians. Epilepsy Behav 13: 316-322.

29. World Health Organization (1999) Raising awareness, fighting stigma improving care.

30. Shorvon SD, Farmer PJ (1988) Epilepsy in developing countries: a review of epidemiological, sociocultural and treatment aspects. Epilepsia 29: S36-S45.

31. (1985) Availability and distribution of antiepileptic drugs in developing countries. III and IV Commissions on Antiepileptic Drugs of the International League Against Epilepsy. Epilepsia 26: 117-121.

32. Adamolekun B, Meinardi H (1990) Problems of drug therapy of epilepsy in developing countries. Trop Geogr Med 42: 178-181.

33. Bodey C (2012) "Epilepsy is pathognomonic of witchcraft": parental perspectives on childhood epilepsy and their treatment choices in South West Uganda. Arch Dis Child 97: A47.

34. Elliott J, Shneker B (2008) Patient, caregiver, and health care practitione knowledge of, beliefs about, and attitudes toward epilepsy. Epilepsy Behav 12: 547-556

35. Ismail H, Wright J, Rhodes $\mathrm{P}$, Small N (2005) Religious beliefs about causes and treatment of epilepsy. Br J Gen Pract 55: 26-31.

36. Shibre T, Alem A, Tekle-Haimanot R, Medhin G, Tessema A, et al. (2008)
Community attitudes towards epilepsy in a rural Ethiopian setting: a re-visit after 15 years. Ethiop Med J 46: 251-259.

37. Atadzhanov M, Haworth A, Chomba EN, Mbewe EK, Birbeck GL (2010) Epilepsy-associated stigma in Zambia: what factors predict greater felt stigma in a highly stigmatized population? Epilepsy Behav 19: 414-418.

38. Frank-Briggs Al, Alikor EA (2011) Knowledge and attitudes of parents toward children with epilepsy. Ann Afr Med 10: 238-242.

39. Mani K, Sidharta P, Pickering C (1994) Educational aspects in the education of health workers, patients and the public. Viewpoints from south India, Indonesia and Kenya. Trop Geogr Med 46: S34-S36.

40. Brown S, Betts T, Chadwick D, Hall B, Shorvon S, et al. (1993) An epilepsy needs document. Seizure 2: 91-103.

41. Gordon K, MacSween J, Dooley J, Camfield C, Camfield P, et al. (1996) Families are content to discontinue antiepileptic drugs at different risks than their physician. Epilepsia 37: 557-562.

42. Wang WZ, Wu JZ, Ma GY, Dai XY, Yang B, et al. (2006) Efficacy assessment of phenobarbital in epilepsy: a large community-based intervention trial in rural China. Lancet Neurol 5: 46-52.

43. Li LM, Fernandes PT, Noronha AL, Marques LH, Borges MA, et al. (2007) Demonstration project on epilepsy in Brazil: outcome assessment. Arq Neuropsiquiatr 65: 58-62.

44. Stephenson BJ, Rowe BH, Haynes RB, Macharia WM, Leon G (1993) The rational clinical examination: Is this patient taking the treatment as prescribed? JAMA 269: 2779-2781.

45. Buelow JM, Smith MC (2004) Medication management by the person with epilepsy: perception versus reality. Epilepsy Behav 5: 401-406. 